Original Research Paper

\title{
Work-Family Enrichment: Its Mediating Role in the Relationships Between Workplace Support Factors and Teachers' Job Satisfaction
}

\author{
${ }^{1} \mathrm{Ng}$ Swee Fung, ${ }^{2}$ Aminah Ahmad and ${ }^{3}$ Zoharah Omar \\ ${ }^{1,3}$ Department of Professional Development and Continuing Education, \\ Faculty of Educational Studies, Universiti Putra Malaysia, 43400 Serdang, Selangor, Malaysia \\ ${ }^{2}$ Institute for Social Science Studies, Universiti Putra Malaysia, 43400 Serdang, Selangor, Malaysia
}

\author{
Article history \\ Received: 10-09-2014 \\ Revised: $10-11-2014$ \\ Accepted: 14-05-2015 \\ Corresponding Author: \\ Aminah Ahmad \\ Institute for Social Science \\ Studies, Universiti Putra \\ Malaysia, 43400 Serdang, \\ Selangor, Malaysia \\ Tel: +60389471871 \\ Faks: +60389471856 \\ Email: aminahahmad49@gmail.com, \\ aminah@upm.edu.my
}

\begin{abstract}
The role of work-family enrichment in the relationships between workplace support factors and employee attitudes at work has not been given much attention. This paper aims to examine whether work-family enrichment mediates the relationships between workplace social support, namely supervisor support and co-worker support and job satisfaction. Selfadministered questionnaires were employed to collect data from 280 teachers working in Malaysian public secondary schools. The data were analyzed using structural equation modelling analyses. Work-family enrichment correlates significantly with supervisor support, co-worker support and job satisfaction. Work-family enrichment functions as a mediator in the relationships between the support factors and job satisfaction. The results indicate that workplace social support enhances work-family enrichment, whereby the skills, knowledge, values and confidence gained at work benefit the family and this enrichment brings about greater job satisfaction. The results underscore the significant role of work-family enrichment in improving job satisfaction.
\end{abstract}

Keywords: Work-Family Enrichment, Job Satisfaction, Organizational Support, Workplace Social Support, Supervisor Support, Co-Worker Support, Teacher

\section{Introduction}

In the educational realm, schools consider teachers' job satisfaction as a key factor in improving educational performance (Sargent and Hannum, 2005). Several studies indicate that job satisfaction influences teacher performance in terms of teachers' relations to students (Van den Berg, 2002) and teacher enthusiasm (Weiqi, 2007) and motivation to leave the teaching profession (Skaalvik and Skaalvik, 2011). In Malaysia, there was an increase in the number of teachers who opted for early retirement or resigned from work during the period from 2008 to 2011 (Ministry of Education, Malaysia, 2012). Since the increase in the number of teachers leaving the profession is an important outcome of job dissatisfaction (Skaalvik and Skaalvik, 2011), the factors that could help improve teacher job satisfaction should be further investigated.

In investigating work and non-work or family-related factors influencing job satisfaction, the demographic changes in the labor force participation of women play a role. With the increase in the labor force participation rate of Malaysian women from $45.7 \%$ in 2008 to $52.4 \%$ in 2013 (Department of Statistics, Malaysia, 2014), the percentage of female teachers also increased from $67.9 \%$ in 2008 (Ministry of Education, Malaysia, 2008) to $69.2 \%$ in 2013 (Ministry of Education, Malaysia, 2013). More than half of the total women employed were married and the proportion increased from 56.8\% in 2008 (Department of Statistics, Malaysia, 2010) to $59.7 \%$ in 2013 (Department of Statistics, Malaysia, 2014). With more married women in the labor force, there exists an increased number of dual-career couples who have to wrestle with the dilemma of managing work and family roles (Galinsky et al., 2011) since work and family are two main domains occupied by couples (Butler et al., 2005). Dual-career couples are faced with the challenge of supporting each other's career, while juggling with childcare, parent care, housework and their 
personal relationships (Grzywacz, 2000). A study in Malaysia has shown that dual-career couples who are occupied with both work and family responsibilities have to deal with work-related demands which restrict the performance of family responsibilities and vice versa (Aminah and Zoharah, 2008).

Expansion theorists (Marks, 1977; Sieber, 1974) do agree that occupying multiple roles such as work and family roles can lead to conflict and stress but there is a possibility that having multiple work and family roles may lead to positive effects such as improved psychological health and well-being (Barnett and Hyde, 2001). Previous research by Brough and O'Driscoll (2005) had largely focused on the negative aspects of work-family interface, while ignoring its positive aspects. However, researchers have begun to recognize the positive aspects of work and family roles (Carlson et al., 2006; McNall et al., 2010a; Noraani et al., 2011; Shein and Chen, 2011). According to Friedman and Greenhaus (2000), work and family operate as "allies" more so than "enemies". Greenhaus and Powell (2006) viewed "work-family enrichment" as an exchange where cross-fertilization of ideas takes place between work and family roles thus improving the quality of life in the latter role. For example, work effectively develop skills, knowledge, values and confidence-resources which can benefit the family. Several attempts have been made by researchers to provide labels to help describe the positive aspect of work and family interface; enhancement (Ruderman et al., 2002), enrichment (Greenhaus and Powell, 2006; Wayne et al., 2006), positive spillover (Crouter, 1984; Edwards and Rothbard, 2000; Hanson et al., 2006), synergy (Beutell and Wittig-Berman, 2008) and facilitation (Frone, 2003; Hill, 2005). However, according to Hammer and Hanson (2006), the distinctions among these labels have yet to be fairly understood and hence causing the labels to be used interchangeably by researchers (Wayne, 2009). However, other researchers have argued that these labels have related yet distinct constructs (Hanson et al., 2006; Wayne, 2009). Since work-family enrichment has been commonly used in studies examining the positive side of work-family interface, we have used this term in this study.

One of the important antecedents of work-family enrichment is social support. Cobb (1976) defined social support as information fed by another which builds an individual's perception that he or she is being cared for and loved (emotional support), esteemed and valued (affirmative support) and is accepted as part of a network of communication and mutual support (network support). House (1981) distinguishes four kinds of support which are emotional support (providing sympathy, care, love and trust), instrumental support (helping directly by providing goods or services), appraisal support (providing information relevant to self-evaluation) and informational support (providing advice, information and suggestions). Workplace social support refers to interpersonal relationships and social interactions with a supervisor or co-worker that help to protect an individual from the detrimental effects of stress (Nielson et al., 2001). Supervisor and co-worker instrumental support refers to the direct assistance or advice given by the supervisor and co-worker that helps the individual to fulfill his or her responsibilities (Frone et al., 1997). Carlson et al. (2007) suggested that individuals having supportive supervisors and co-workers tend to attain a sense of energy and confidence from work that enhances the family domain. Similarly, Grzywacz and Marks (2000) reported that higher levels of social support from supervisors and coworkers were associated with greater positive spillover from work to family. Mahony et al. (2010) indicated that organizational support progressively impacts employees' job satisfaction.

Although work-family interface factors and their outcomes, including job satisfaction, have been widely studied (Yildirim and Aycan, 2008; Lapierre et al., 2008; Lu et al., 2008; Noryati et al., 2009), few studies have focused on teachers (Cinamon and Rich, 2005). The mediating role of work-family enrichment was first reported by McNall et al. (2010b). From a study sample of working adults, the researchers found that workfamily enrichment played a mediating role between flexible work arrangements and two outcomes, namely job satisfaction and turnover intention. Later, In Malaysia, Noraani et al. (2011) studied the mediating effects of work-family facilitation and family satisfaction. An analysis of a sample of middle-aged working single mothers established the presence of mediating effects of work-family enrichment on the relationships between job demands and employees' intention to stay. Other studies conducted on the role of work-family enrichment as the mediator by researchers in Malaysia, include those by Wan Rashid et al. (2011) who studied social support factors as the independent variables and life satisfaction as the outcome and who studied job factors as the independent variables and job satisfaction as the outcome. The role of work-family enrichment as a mediator in the support-satisfaction link has recently been studied among employees in China by Tang et al. (2014). Despite these studies, there is still a need for more research on how work-family enrichment is linked with social support and workrelated outcomes. This present study was conducted to examine the mediating role of work-family enrichment in the relationships between workplace social support (supervisor support and co-worker support) and job satisfaction among teachers in Malaysia. The present study will only focus on workfamily enrichment as it is more strongly related to 
work-related outcomes, such as job satisfaction, than family-work enrichment (McNall et al., 2010a; Wayne et al., 2006; Carlson et al., 2014). In addition, Russo and Buonocore (2012) reported that workfamily enrichment and not family-work enrichment, relates to work-related outcomes. The term "workfamily enrichment" used in this study is synonymous to "work-to-family enrichment" used by McNall et al. (2010b) and work-to-family enhancement used by Voydanoff (2004).

\section{Literature Review and Hypotheses}

\section{Relationship between Supervisor Support and Job Satisfaction}

Past studies have shown the link between supervisor support and job satisfaction. Hsu (2011) did a study on correctional officers in institutions such as prisons, drug abuse treatment centers, detention centers, training institutes, juvenile correction schools and hospitals and the results indicated that family support from supervisors significantly predicted job satisfaction (Odle-Dusseau et al., 2012). In another longitudinal study on work-family enrichment among Taiwanese employees, similar results were found $(\mathrm{Lu}$, 2011). Supervisors who were willing to be flexible were likely to be perceived as supportive (Hopkins, 2002). Studies revealed that employees whose supervisors were supportive experienced greater satisfaction with their jobs (Allen, 2001; Hill, 2005; $\mathrm{Ng}$ and Sorensen, 2008; Thompson and Prottas, 2005).

However, contrary to the findings of these studies, a study conducted in the United States by Clark (2001) and another study conducted in India by Baral and Bhargava (2010) did not support the link between supervisor support and employee job satisfaction. Despite these contradictory findings, most of the earlier studies seem to support the positive relationship between supervisor support and job satisfaction and hence the following hypothesis was formulated.

H1: There is a positive relationship between supervisor support and job satisfaction.

\section{Relationship between Co-Worker Support and Job Satisfaction}

According to a study by Thompson and Prottas (2005), support from co-workers was positively related to job satisfaction. Similar results were reported by Roxburgh (1999). Ducharme and Martin (2000) found that both affective and instrumental coworker support were positively related to job satisfaction. $\mathrm{Ng}$ and Sorensen (2008) did a metaanalysis on this support-satisfaction link and the analysis revealed that social support from co-workers increased employees' job satisfaction. Similarly, this support-satisfaction link was reported by Kinman et al. (2011). Based on the findings of these studies, we formulated the following hypothesis.

H2: There is a positive relationship between co-worker support and job satisfaction.

\section{Relationship between Supervisor Support and Work-Family Enrichment}

Taylor et al. (2009) examined the effect of supervisor support on work-family enrichment among Hispanic business professionals in the United States. The researchers found that a higher level of supervisor support leads to a higher level of work-family enrichment. A positive relationship between supervisor support and work-family enrichment in a sample of employed workers irrespective of occupational group in the Australian construction industry was also reported by Lingard et al. (2010). Beutell and Wittig-Berman (2008) conducted a study to explore generational effects affecting work-family synergy or enrichment. They found that supervisor support was the strongest predictor of work-family synergy for each generational group. Bhargava and Baral (2009) found a positive relationship between supervisor support and work-family enrichment in a study which involved managerial employees working in manufacturing and information technology sectors in India. Support provided by supervisors (school principals and heads of departments) was found to significantly predict work-family enrichment in a sample of female teachers in Israel (Cinamon and Rich, 2010). Furthermore, a longitudinal study of Mainland Chinese workers indicates a significant connection between supervisor support and work-family enrichment (Siu et al., 2010). The positive relationship between supervisor support and workfamily enrichment was also reported by other researchers (Baral and Bhargava, 2011; Beham et al., 2011; Hill, 2005; Karatepe and Bekteshi, 2008; Thompson and Prottas, 2005; Voydanoff, 2004; Wadsworth and Owens, 2007).

On the contrary, the findings of a study conducted in India did not support the positive relationship between supervisor support and work-family enrichment (Aryee et al., 2005). It should be pointed out that Aryee et al. (2005) global measure of social support did not include both supervisor support and co-worker support as two distinct sources and hence this may have resulted in the non-predicting role of supervisor support on work-family enrichment. Based on the substantial literature that supports the link between these two variables, the following hypothesis was postulated. 
H3: There is a positive relationship between supervisor support and work-family enrichment.

\section{Relationship between Co-Worker Support and Work-Family Enrichment}

Co-worker support is less frequently studied than supervisor support in work-family enrichment studies. Co-worker support is another aspect of the informal work environment that may influence an employee's ability to integrate work and family roles (Thompson and Prottas, 2005). Lu et al. (2009) examined the effects of co-worker support on the level of work-family enrichment among working parents in China. The results indicated that employees whose co-workers were more family-friendly or supportive tended to experience greater work-family enrichment. A study by Beham et al. (2011) on German service sector employees in the information technology, retail and healthcare industries revealed that co-worker support was positively related to work-home enrichment. Acknowledging the fact that previous studies have shown the link between coworker support and work-family enrichment, we formulated the following hypothesis.

H4: There is a positive relationship between co-worker support and work-family enrichment

\section{Relationship between Work-Family Enrichment and Job Satisfaction}

McNall et al. (2010a) conducted the first metaanalysis on the positive side of the work-family interface and its outcomes. Work-family enrichment was more strongly associated with work-related variables (e.g., job satisfaction) whereas family-work enrichment was more strongly associated with nonwork related variables (e.g., family satisfaction). Similarly, Russo and Buonocore (2012; Carlson et al., 2010; 2014) found that work-family enrichment was more strongly correlated with job satisfaction than with family satisfaction.

A study by Aryee et al. (2005) which involved fulltime working fathers and mothers in India found that work-family enrichment was positively related to job satisfaction. Lu et al. (2009) examined the relationship between work-family facilitation and job satisfaction among employed parents in China and found similar results. Hassan et al. (2009) reported that work-family enrichment increased employees' job satisfaction in a study of employees from three public and three private sector organizations in Sarawak, Malaysia. Similar results were reported by (McNall et al., 2010b; Jaga and Bagraim, 2011; Masuda et al., 2012). A longitudinal study of Taiwanese employees by Lu (2011) reported a significant positive relationship between work-family enrichment and job satisfaction. More recently, Russo and Buonocore (2012) reported similar results in their study on nurses working in public hospitals and private clinics in Italy. Based on the findings of these studies, we proposed the following hypothesis.

H5: There is a positive relationship between work-family enrichment and job satisfaction

\section{Work-Family Enrichment as Mediator}

The mediation model draws upon the principles of the Conservation of Resources (COR) theory (Hobfoll, 1989), the work-family enrichment model (Greenhaus and Powell, 2006) and the theory of social exchange (Blau, 1964). In essence, the COR theory suggests that individuals are inclined to seek and maintain resources to reduce stress-resources being objects, personal characteristics, conditions, energies and social support. This study employs the COR theory to gain insights into the relationships between social support factors and job satisfaction. Supervisor and co-worker support are resources gained which can reduce stress (e.g., job dissatisfaction) and more importantly contribute to the enrichment process (Friedman and Greenhaus, 2000). According to the work-family enrichment model (Greenhaus and Powell, 2006), different resources can be acquired from one role to improve performance in another role. These resources include, among others, social support such as supervisor and co-worker support.

The support could improve performance directly (referred to as instrumental support) or indirectly (referred to as affective support). In addition to the enrichment model, the theory of social exchange (Blau, 1964) is used to gain an understanding of the relationship between enrichment and work-related outcomes, specifically job satisfaction. This theory, which is applied to the work-family dynamics and their subsequent outcomes, will help understand employees' perceptions and responses toward workplace support. Employees acknowledge the support they receive by reciprocating with more positive work attitudes such as greater work satisfaction (McNall et al., 2010a).

Based on the model of work-family enrichment, the COR theory, the social exchange theory and previous empirical findings, we predict that higher levels of social support could lead to greater experience of work-family enrichment and this enrichment has the potential to increase the levels of job satisfaction and hence, the following hypotheses were formulated.

HE: Work-family enrichment mediates the relationship between supervisor support and job satisfaction.

HE:Work-family enrichment mediates the relationship between co-worker support and job satisfaction. 


\section{Method}

\section{Sample and Procedures}

Employing a two-stage sampling method, data were collected from randomly selected public secondary schools in Bangsar Zone, located in the capital city of Kuala Lumpur. Teachers from these schools were then selected using simple random sampling. Considering previous research (Grzywacz and Marks, 2000; Siu et al., 2010; Van Steenbergen et al., 2007) as guiding resources, this study used a more encompassing sample, without excluding married teachers without children, thus moving away from narrow conceptualizations of the family. Nevertheless, the study sample did not include teachers who had serious illnesses and those undergoing practical training, as well as replacement teachers. Self-administered questionnaires were dispatched using the drop and collect method. Out of a total of 301 teachers in the sample, $280(93 \%)$ responded to the questionnaires whereby 218 were females and 62 were males. The mean age reported was 36.51 years $(\mathrm{SD}=8.12)$ and the teachers had worked for an average of 11.36 years $(\mathrm{SD}=$ 8.21). The proportion of married teachers was high, slightly more than three quarters $(79 \%)$ of the teachers who responded. In terms of educational attainment, most of the teachers $(87.5 \%)$ had a bachelor's degree while the rest $(12.5 \%)$ a postgraduate degree.

\section{Measurement}

\section{Social Support}

To measure supervisor and co-worker social support, the study used an adapted version of a six-item scale used by Aminah (1997), whereby four items were originally developed by Caplan et al. (1975) and two items by Letiecq et al. (1996). This six-item scale was employed to measure each source of workplace social support, specifically supervisor and co-worker support. Examples of items for supervisor support include "How often does your supervisor talk to you about your workrelated problem" and "How often does your supervisor talk to you about your family problem?" Similar items were used to measure co-worker support. Each teacher was requested to state the frequency of support received from each source, using a five-point Likert scale with a range from $1=$ never to $5=$ always. Aminah (1997) reported a reliability coefficient (alpha) of 0.86 for the supervisor support scale and 0.81 for the co-worker scale.

\section{Job Satisfaction}

Six items adapted from Clark (2001) were used to measure job satisfaction. The teachers provided their responses using the five-point Likert scale which ranges from 1 = strongly disagree to $5=$ strongly agree. Examples of items include "I find my activities at work to be personally meaningful" and "I am very satisfied with this job". Clark (2001) reported an internal consistency reliability of 0.91 .

\section{Work-Family Enrichment}

Work-family enrichment was measured using the nine-item scale by Carlson et al. (2006), which consists of three items for work-to-family development, (e.g., "My involvement in work helps me to understand different viewpoints and this helps me be a better family member"), three items for workto-family affect (e.g., "My involvement in work puts me in a good mood and this helps me be a better family member") and another three items for work-tofamily capital (e.g., "My involvement in work helps me feel personally fulfilled and this helps me be a better family member"). The questionnaire provided the five-point Likert scale response options ranging from 1 = strongly disagree to 5 = strongly agree. Carlson et al. (2006) reported a reliability coefficient (alpha) of 0.92 for the nine-item scale.

\section{Data Analysis}

Descriptive statistics, comprising means, standard deviations and correlations between variables, were calculated. The direct, indirect and mediated models were tested using the Structural Equation Modeling (SEM) procedure. The SEM procedure incorporates the measurement and structural models (Iacobucci, 2008). The number of respondents for this study which consisted of 280 teachers had met the minimum requirement (200 respondents) for the use of SEM (Hoe, 2008).

\section{Results}

The means, standard deviations, reliability (Cronbach alpha) coefficients and bivariate correlation coefficients are shown in Table 1. For all scales, the Cronbach alpha coefficients ranged from 0.78 to 0.95 , thus surpassing 0.70 minimum acceptable level suggested by Hair et al. (2010). The Average Variance Extracted (AVE) values for all the latent variables exceeded the threshold of 0.50 , indicating that the scales have high convergent validity (Hair et al., 2010). All the bivariate correlation coefficients were significant.

The fit indices of the measurement model are as follows: $\chi 2=274.337, \chi 2 / \mathrm{df}=1.946, \mathrm{AGFI}=0.873$, GFI $=0.905, \mathrm{CFI}=0.960, \mathrm{RMSEA}=0.058$ and $\mathrm{IFI}=0.961$. Three of these indices (CFI, TLI and IFI) exceed the threshold value of 0.90 . The RMSEA value is within the acceptable range of 0.03 to 0.08 (Hair et al., 2010). 
Chi-square $(\mathrm{df})=274.337(141) ; \mathrm{P}$ value $(>=0.05)=0.000$;

Relative Chi-sq $(<=5)=1.946 ;$ AGFI $(>=0.9)=0.873$;

GFI $(>=0.9)=0.905$; CFI $(>=0.9)=0.960$;

IFI $(>=0.9)=0.961 ;$ RMSEA $(<=0.08)=0.058$;

RMR $(<=0.08)=0.075$

(Standardized estimate)

\author{
8
}

(2)

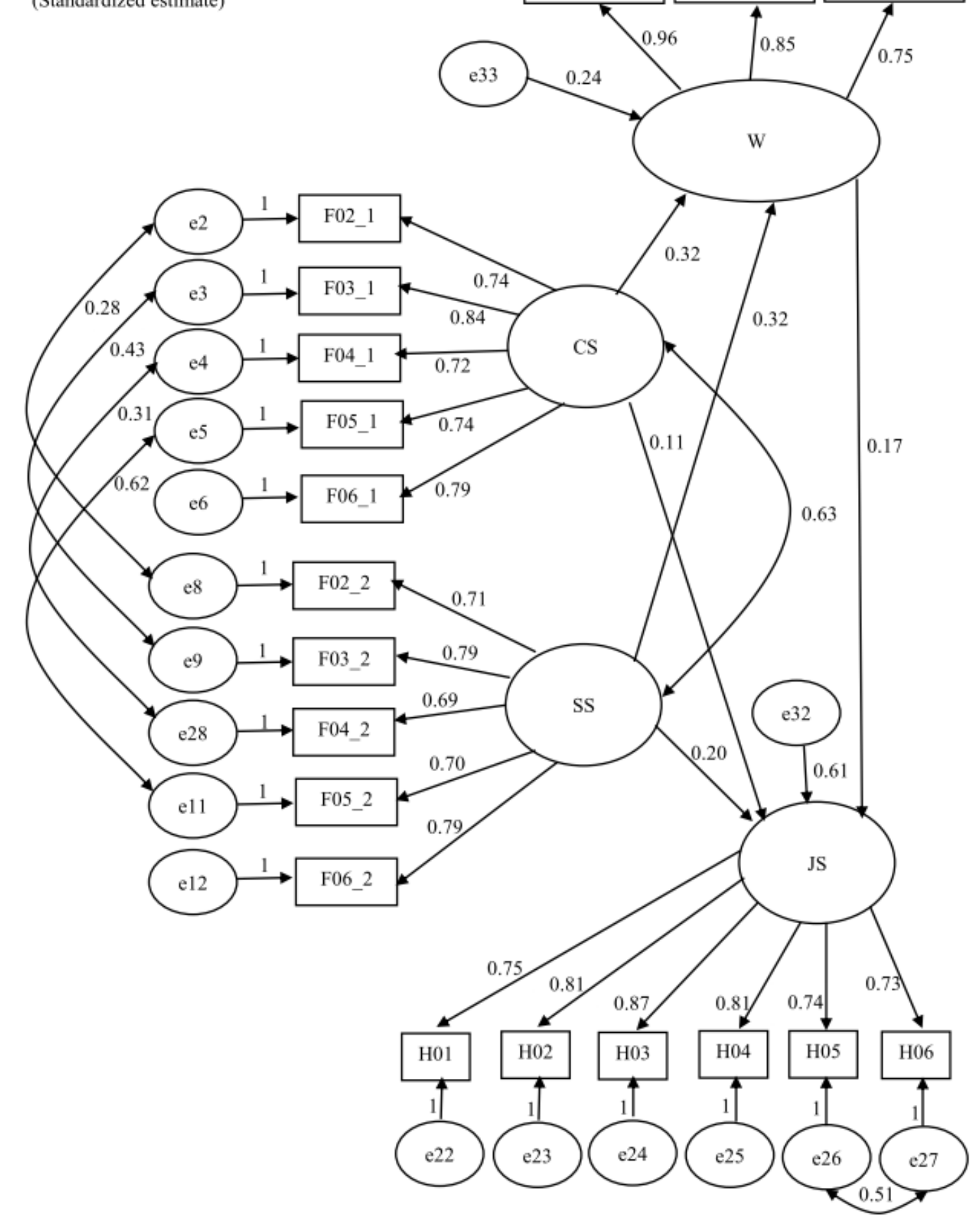

Fig. 1. Estimated path coefficients of the full mediation model; Note: $\mathrm{CS}=$ co-worker support, $\mathrm{SS}=$ supervisor support, $\mathrm{W}=$ workfamily enrichment, JS = job satisfaction 
Table 1. Descriptive statistics, reliability coefficients, AVE estimates and correlation coefficients

\begin{tabular}{llllllll}
\hline Variables & Mean & SD & $\alpha$ & CS & SS & W & JS \\
\hline CS & 3.37 & 0.57 & 0.88 & -0.588 & & \\
SS & 3.29 & 0.57 & 0.87 & $0.174^{*}$ & -0.546 & -0.738 \\
W & 3.79 & 0.65 & 0.95 & $0.376^{* * *}$ & $0.373^{* * *}$ & $0.732^{* *}$ \\
JS & 3.74 & 0.66 & 0.91 & $0.382^{* * *}$ & $0.457^{* * *}$ & -0.618 \\
\hline
\end{tabular}

Note: $* * * \rho<0.001,{ }^{*} \rho<0.05, \alpha=$ Cronbach alpha reliability values, AVE $=$ average variance extracted, AVE estimates are presented in parenthesis, $\mathrm{CS}=$ co-worker support, $\mathrm{SS}=$ supervisor support, $\mathrm{W}=$ work-family enrichment, $\mathrm{JS}=$ job satisfaction

Table 2. Model fit summary and structural model comparison

\begin{tabular}{lccccccrr}
\hline Model & $\chi^{2}$ & $\frac{X^{2}}{d f}$ & AGFI & GFI & CFI & RMSEA & TLI & IFI \\
\hline Mediation model & 274.337 & 1.946 & 0.873 & 0.905 & 0.960 & 0.058 & 0.952 & 0.961 \\
Indirect model & 293.298 & 2.051 & 0.868 & 0.900 & 0.955 & 0.061 & 0.946 & 0.955 \\
Direct model & 466.821 & 3.242 & 0.820 & 0.864 & 0.904 & 0.090 & 0.885 & 0.904 \\
\hline
\end{tabular}

Table 3. Standardized regression weights

\begin{tabular}{llllll} 
Dependent variables & & Independent variables & Mediation model & Indirect model & Direct model \\
\hline W & $\leftarrow$ & CS & $0.321^{* * *}$ & $0.328^{* * *}$ & \\
W & $\leftarrow$ & SS & $0.317^{* * *}$ & $0.335^{* * *}$ \\
JS & $\leftarrow$ & W & $0.635^{* * *}$ & $0.761^{* * *}$ & $0.312^{* * *}$ \\
JS & $\leftarrow$ & CS & $0.109^{*}$ & & $0.403^{* * *}$ \\
JS & $\leftarrow$ & SS & $0.202^{* * *}$ & & \\
\hline
\end{tabular}

Note: $* * * \rho<0.001,{ }^{*} \rho<0.05, \mathrm{CS}=$ co-worker support, $\mathrm{SS}=$ supervisor support, $\mathrm{W}=$ work-family enrichment, JS = job satisfaction

Alternative structural models were tested against each other to test the research hypotheses. The mediation model was compared to a competing indirect model in which all path coefficients from organizational support to job satisfaction were constrained to zero and to a competing direct model in which all path coefficients to and from work-family enrichment were constrained to zero. As shown in Table 2, the values of the indices for the mediation model indicate a significantly better fit to the data compared to those for the indirect and direct models.

Table 3 presents the path and parameter estimates of the mediation, as well as indirect and direct models. To test Hypotheses 1 to 5, Confirmatory Factor Analysis (CFA) using maximum likelihood estimation was conducted. Significant direct effects of supervisor support $(\beta=0.403, \mathrm{p}<0.001)$ and co-worker support $(\beta=$ $0.312, \mathrm{p}<0.01)$ on job satisfaction suggest that the direct effect condition was satisfied, thus supporting Hypotheses 1 and 2. The path coefficients for this model indicate that co-worker support $(\beta=0.321, \mathrm{p}<0.001)$ and supervisor support $(\beta=0.317, \quad \mathrm{p}<0.001)$ were significantly related to work-family enrichment which support Hypotheses 3 and 4 . The results indicate a significant relationship between work-family enrichment and job satisfaction $(\beta=0.635, \mathrm{p}<0.001)$, thus supporting Hypothesis 5 .

The test of the mediation model showed that the direct effect of supervisor support on job satisfaction $(\beta$ $=0.202, \mathrm{p}=0.001$ ) and co-worker support on job satisfaction $(\beta=0.109, \mathrm{p}=0.001)$ decreased but remain significant upon the addition of work-family enrichment acting as the mediator in the model. This suggests that work-family enrichment partially mediates the relationships between supervisor support and co-worker support and job satisfaction. Hence, Hypothesis 6 and 7 were supported.

As shown in Fig. 1, the coefficient of determination $\left(\mathrm{R}^{2}\right)$ of 0.24 implies that co-worker support and supervisor support jointly explained $24 \%$ of the variance in work-family enrichment. Overall, $61 \%$ of the variance in job satisfaction was accounted for by co-worker support, supervisor support and workfamily enrichment.

\section{Discussion}

The present study found significant relationships between supervisor support and co-worker support and work-family enrichment. The advice, emotional support and assistance received from supervisors and co-workers generate a positive effect-a sense of energy and confidence gained from work which could enhance family functioning. These findings are in line with those by (Hsu, 2011; Odle-Dusseau et al., 2012; Lu, 2011; Beham et al., 2011; Lu et al., 2009; Ng and Sorensen, 2008; Thompson and Prottas, 2005).

Consistent with the findings reported by previous researchers (Aryee et al., 2005; Hassan et al., 2009; Lu, 2011; Russo and Buonocore, 2012), this study found a significant enrichment-satisfaction relationship, whereby teachers who reported higher levels of work-family enrichment experienced greater job satisfaction. The findings indicate that the skills, knowledge, values and 
confidence gained at work could benefit the family and this brings about greater job satisfaction.

Pertaining to the mediation effect of work-family enrichment on the relationship between supervisor and co-worker support and job satisfaction, the results show that teachers receiving more supervisor and co-worker support tend to experience enhanced enrichment and this would lead to greater job satisfaction. The findings suggest that the work-family enrichment model (Greenhaus and Powell, 2006) could help explain the mediation research framework.

The findings of this study demonstrate that supervisor support and co-worker support are important factors related to employees' experiences of work-family enrichment and job satisfaction. In this study, support from supervisor and co-workers seems to be effective in predicting enrichment. Teachers who receive favorable assistance from their supervisors and coworkers are involved in the "norm of reciprocity" as explained by Gouldner (1960), reciprocating the support with positive work attitudes.

From a theoretical perspective, the findings contribute toward the growing literature on work-family enrichment and support the model of work-family enrichment (Greenhaus and Powell, 2006) which explains the resource generation process and occurrence of enrichment. The findings provide additional evidence on the antecedents and consequences associated with workfamily enrichment. The COR theory, which also serves as a theoretical foundation of this study, is supported, thus providing an understanding of how resources are attained and utilized to achieve a positive experience in workfamily interaction. The resources gained, namely supervisor and co-worker support could reduce the experience of stress in the form of job dissatisfaction. The findings also support the use of social exchange theory in explaining the relationship between work-family enrichment and job satisfaction, in accordance with the norm of reciprocity. When teachers attain work-family enrichment, they are more likely to reciprocate by having more positive attitudes toward their job.

In this study, it is evident that teachers received valuable support from their supervisors and coworkers. Teachers who have to perform multiple roles, such as class teacher, head panel of a subject as well as co-curricular activity advisor, have different supervisors who monitor the performance of these different roles. Therefore, the school management should take proactive steps in creating opportunities for teachers to interact meaningfully with supervisors and co-workers, hence enhancing communication or network support among them. Social programs, such as gatherings and excursions can be organized informally to promote mutual understanding and care or emotional support among teachers.
Supervisors and co-workers can provide substantial social support to teachers through behavior that demonstrates care and willingness to listen to teachers' work-or family-related problems. Teachers tend to receive support from their co-workers possibly because they spend time together in their common room in between teaching periods whereby they have greater opportunities to interact and acquire support. This support would generate greater positive spillover from work to family and hence results in the experience of higher levels of job satisfaction.

This study acknowledges several limitations. This being a self-report and cross-sectional study restricts one from inferring causality. Another limitation of the study is related to its sample. The results of the study may be generalized to teachers working in public but not private schools in Malaysia, since the working conditions of the two types of schools may differ.

\section{Conclusion}

supervisor and co-worker support are important antecedents of job satisfaction. Work-family enrichment mediates the relationships between these support factors and job satisfaction. A teacher who receives more support tends to experience greater work-family enrichment and will in turn attain greater job satisfaction. This mediation process, where workplace social support results in workfamily enrichment and hence enhancing job satisfaction, points to the important role of work-family enrichment in improving job satisfaction.

\section{Funding Information}

The authors have no support or funding to report.

\section{Author's Contributions}

Ng Swee Fung: Contributed to conception, design, acquisition of data and analysis and interpretation of data and writing the article.

Aminah Ahmad: Contributed to conception, design, reviewing of article critically and amendment of article.

Zoharah Omar: Contributed to conception, design and analysis and interpretation of data.

\section{Ethics}

The authors confirm that this work is original and has not been published else were.

\section{References}

Allen, T.D., 2001. Family-supportive work environments: The role of organizational perceptions. J. Vocational Behavior, 58: 414-435. DOI: $10.1006 / j v b e .2000 .1774$ 
Aminah, A., 1997. Work-family conflict and social support: A study of female secretaries in Malaysia. Pertanika J. Social Sci. Humanities, 5: 93-101.

Aminah, A. and O. Zoharah, 2008. Gender differences in work-family conflict and family-friendly employment policy practices. Int. J. Humanities, 6: 15-26.

Aryee, S., E.S. Srinivas and H.H. Tan, 2005. Rhythms of life: Antecedents and outcomes of work-family balance in employed parents. J. Applied Psychol., 90: 132-146. DOI: 10.1037/0021-9010.90.1.132

Baral, R. and S. Bhargava, 2010. Work-family enrichment as a mediator between organizational interventions for work-life balance and job outcomes. J. Manage. Psychol., 25: 274-300.

DOI: $10.1108 / 02683941011023749$

Baral, R. and S. Bhargava, 2011. Examining the moderating influence of gender on the relationships between work-family antecedents and work-family enrichment. Gender Manage. Int. J., 26: 122-147. DOI: $10.1108 / 17542411111116545$

Barnett, R.C. and J.S. Hyde, 2001. Women, men, work and family. Am. Psychol., 56: 781-796. DOI: 10.1037/0003-066X.56.10.781

Beham, B., S. Drobnič and P. Präg, 2011. Work demands and resources and the work-family interface: Testing a salience model on German service sector employees. J. Vocational Behavior, 78: 110-122. DOI: 10.1016/j.jvb.2010.07.008

Beutell, N.J. and U. Wittig-Berman, 2008. Work-family conflict and work-family synergy for generation X, baby boomers and matures: Generational differences, predictors and satisfaction outcomes. J. Manag. Psychol., 23: 507-523.

DOI: $10.1108 / 02683940810884513$

Bhargava, S. and R. Baral, 2009. Antecedents and consequences of work-family enrichment among Indian managers. Psychol. Studies, 54: 213-225. DOI: $10.1007 / \mathrm{s} 12646-009-0028-\mathrm{z}$

Blau, P., 1964. Exchange and Power in Social Life. 1st Edn., New York, ISBN-10: 1412823153, pp: 352.

Brough, P. and M. O'Driscoll, 2005. Work-Family Conflict and Stress. In: Edward Elgar Publishing, Antoniou, A. and C. Cooper, (Eds.), Cheltenham, England, pp: 346-365.

Butler, A., J. Grzywacz, B. Bass and K. Linney, 2005. Extending the demands-control model: A daily diary study of job characteristics, work-family conflict and work-family facilitation. J. Occupat. Organ. Psychol., 78: 155-169. DOI: 10.1348/096317905X40097

Caplan, R.D., S. Cobb, J.R.P. French, R. Van Harrison and S.R. Pinneau, 1975. Job demands and worker health. Institute for Social Research: Ann Arbor, MI.
Carlson, D.S., J.G. Grzywacz and K.M. Kacmar, 2010. The relationship of schedule flexibility and outcomes via the work-family interface. J. Manag. Psychol., 25: 330-355. DOI: $10.1108 / 02683941011035278$

Carlson, D.S., E.M. Hunter, M. Ferguson and D. Whitten, 2014. Work-family enrichment and satisfaction mediating processes and relative impact of originating and receiving domains. J. Manage., 40: 845-865. DOI: 10.1177/0149206311414429

Carlson, D.S., K.M. Kacmar, J.H. Wayne and J.G. Grzywacz, 2006. Measuring the positive side of the work-family interface: Development and validation of a work-family enrichment scale. J. Vocat. Behavior, 68: 131-164.

DOI: $10.1016 /$ j.jvb.2005.02.002

Carlson, D.S., K.M. Kacmar, J.H. Wayne and J.G. Grzywacz, 2007. Work-family facilitation: A theoretical explanation and model of primary antecedents and consequences. Hum. Resource Manage. Rev., 17: 63-76.

DOI: $10.1016 /$ j.hrmr.2007.01.002

Cinamon, R.G. and Y. Rich, 2005. Work-family conflict among female teachers. Teach. Teacher Edu., 21: 365-378. DOI: 10.1016/j.tate.2004.06.009

Cinamon, R.G. and Y. Rich, 2010. Work family relations: Antecedents and outcomes. J. Career Assess., 18: 59-70. DOI: $10.1177 / 1069072709340661$

Clark, S.C., 2001. Work cultures and work/family balance. J. Vocat. Behavior, 58: 348-365. DOI: $10.1006 /$ jvbe.2000.1759

Cobb, S., 1976. Social support as a moderator of life stress. Psychosomatic Med., 38: 300-314. DOI: 10.1097/00006842-197609000-00003

Crouter, A.C., 1984. Spillover from family to work: The neglected side of the work-family interface. Hum. Relat., 37: 425-442. DOI: $10.1177 / 001872678403700601$

Department of Statistics, Malaysia, 2010. Yearbook of Statistics Malaysia. Department of Statistics, Malaysia, Kuala Lumpur.

Department of Statistics, Malaysia, 2014. Labour Force Survey Report Malaysia 2013. Department of Statistics, Malaysia.

Ducharme, L.J. and J.K. Martin, 2000. Unrewarding work, coworker support and job satisfaction a test of the buffering hypothesis. Work Occupat., 27: 223-243. DOI: 10.1177/0730888400027002005

Edwards, J.R. and N.P. Rothbard, 2000. Mechanisms linking work and family: Clarifying the relationship between work and family constructs. Acad. Manage. Rev., 25: 178-199.

DOI: $10.5465 / A M R .2000 .2791609$ 
Friedman, S.D. and J.H. Greenhaus, 2000. Work and Family--allies Or Enemies?: What Happens when Business Professionals Confront Life Choices. 1st Edn., Oxford University Press, Oxford, ISBN-10: 019511275X, pp: 271.

Frone, M.R., 2003. Work-Family Balance. In: Handbook of Occupational Health Psychology, Quick, J.C. and L.E. Tetrick (Eds.), American Psychological Association, Washington DC, pp: 143-162. DOI: $10.1037 / 10474-007$

Frone, M.R., J.K. Yardley and K.S. Markel, 1997. Developing and testing an integrative model of the work-family interface. J. Vocat. Behavior, 50: 145-167. DOI: 10.1006/jvbe.1996.1577

Galinsky, E., K. Aumman and J.T. Bond, 2011. Times are changing: Gender and generation at work and at home. Families Work Institute.

Gouldner, A.W., 1960. The norm of reciprocity: A preliminary statement. Am. Sociological Rev., 25: 161-178. DOI: $10.2307 / 2092623$

Greenhaus, J.H. and G.N. Powell, 2006. When work and family are allies: A theory of work-family enrichment. Acad. Manage. Rev., 31: 72-92.

DOI: 10.5465/AMR.2006.19379625

Grzywacz, J.G., 2000. Work-family spillover and health during midlife: Is managing conflict everything? Am. J. Health Promot., 14: 236-243.

DOI: $10.4278 / 0890-1171-14.4 .236$

Grzywacz, J.G. and N.F. Marks, 2000. Family, work, work-family spillover and problem drinking during midlife. J. Marriage Family, 62: 336-348. DOI: 10.1111/j.1741-3737.2000.00336.x

Hair, J.F., W.C. Black, B.J. Babin, R.E. Anderson and R.L. Tatham, 2010. Multivariate Data Analysis. 7th Ed. Prentice Hall, Englewood Cliffs (NJ).

Hammer, L.B. and G. Hanson, 2006. Work-Family Enrichment. In: Encyclopedia of Career Development, Greenhaus, J.H. and G.A. Callanan, (Eds.), SAGE Publications, Thousand Oaks, ISBN-10: 1452265577, pp: 869-871.

Hanson, G.C., L.B. Hammer and C.L. Colton, 2006. Development and validation of a multidimensional scale of perceived work-family positive spillover. J. Occupat. Health Psychol., 11: 249-265.

DOI: 10.1037/1076-8998.11.3.249

Hassan, Z., M.F. Dollard and A.H. Winefield, 2009. Work-Family Enrichment: Sharing Malaysians' Experiences. Proceedings of the 8th Industrial Organisational Psychology Conference, (OOP' 09), Australian Psychological Society, Sydney, pp: 57-62.

Hill, E.J., 2005. Work-family facilitation and conflict, working fathers and mothers, work-family stressors and support. J. Family Issues, 26: 793-819.

DOI: $10.1177 / 0192513 \times 05277542$
Hobfoll, S.E., 1989. Conservation of resources: A new attempt at conceptualizing stress. Am. Psychologist, 44: 513-524. DOI: 10.1037/0003-066X.44.3.513

Hoe, S.L., 2008. Issues and procedures in adopting structural equation modeling technique. J. Applied Quantitative Methods, 3: 76-83.

Hopkins, K.M., 2002. Interactions of gender and race in workers' help seeking for personal/family problems perceptions of supervisor support and intervention. J. Applied Behavioral Sci., 38: 156-176. DOI: $10.1177 / 00286302038002002$

House, J.S., 1981. Work Stress and Social Support. 2nd Edn., Addison-Wesley Longman, Incorporated, Reading, ISBN-10: 0201031019, pp: 156.

Hsu, Y.R., 2011. Work-family conflict and job satisfaction in stressful working environments: The moderating roles of perceived supervisor support and internallocusof control. Int. J. Manpower, 32: 233-248. DOI: 10.1108/01437721111130224

Iacobucci, D., 2008. Mediation Analysis. 1st Edn., SAGE Publications, Los Angeles, ISBN-10: 141292569X, pp: 85.

Jaga, A. and J. Bagraim, 2011. The relationship between work-family enrichment and work-family satisfaction outcomes. South Afr. J. Psychol., 41: 52-62. DOI: 10.1177/008124631104100106

Karatepe, O.M. and L. Bekteshi, 2008. Antecedents and outcomes of work-family facilitation and familywork facilitation among frontline hotel employees. Int. J. Hospitality Manage., 27: 517-528. DOI: 10.1016/j.ijhm.2007.09.004

Kinman, G., S. Wray and C. Strange, 2011. Emotional labour, burnout and job satisfaction in UK teachers: The role of workplace social support. Int. J. Experim. Edu. Psychol., 31: 843-856. DOI: $10.1080 / 01443410.2011 .608650$

Lapierre, L.M., P.E. Spector, T.D. Allen, S. Poelmans and C.L. Cooper et al., 2008. Family-supportive organization perceptions, multiple dimensions of work-family conflict and employee satisfaction: A test of model across five samples. J. Vocat. Behavior, 73: 92-106. DOI: 10.1016/j.jvb.2008.02.001

Letiecq, B.L., E.A. Anderson and S.A. Koblinsky, 1996. Social support of homeless and permanently housed low-income mothers with young children. Family Relations, 45: 265-272.

Lingard, H., V. Francis and M. Turner, 2010. Workfamily conflict in construction: Case for a finergrained analysis. J. Construct. Eng. Manage., 136: 1196-1206. DOI: $10.1061 /(A S C E) C O .1943-7862.0000229$

Lu, J.F., O.L. Siu, P.E. Spector and K. Shi, 2009. Antecedents and outcomes of a fourfold taxonomy of work-family balance in Chinese employed parents. J. Occupat. Health Psychol., 14: 182-192. DOI: $10.1037 / \mathrm{a} 0014115$ 
Lu, L., 2011. Working hours and personal preference among Taiwanese employees. Int. J. Workplace Health Manage., 4: 244-256. DOI: $10.1108 / 17538351111172608$

Lu, L., S.F. Kao, T.T. Chang, H.P. Wu and C.L. Cooper, 2008. Work/family demands, work flexibility, work/family conflict and their consequences at work: A national probability sample in Taiwan. Int. J. Stress Manage., 15: 1-21. DOI: $10.1037 / 1072-5245.15 .1 .1$

Mahony, D.F., M.A. Hums, D.P. Andrew and S.W. Dittmore, 2010. Organizational justice in sport. Sport Manage. Rev., 13: 91-105. DOI: 10.1016/j.smr.2009.10.002

Marks, S.R., 1977. Multiple roles and role strain: Some notes on human energy, time and commitment. Am. Sociological Rev., 42: 921-936. DOI: $10.2307 / 2094577$

Masuda, A.D., L.A. McNall, T.D. Allen and J.M. Nicklin, 2012. Examining the constructs of work-tofamily enrichment and positive spillover. J. Vocat. Behavior, 80: 197-210. DOI: $10.1016 /$ j.jvb.2011.06.002

McNall, L.A., J.M. Nicklin and A.D. Masuda, 2010a. A meta-analytic review of the consequences associated with work-family enrichment. J. Bus. Psychol., 25: 381-396. DOI: 10.1007/s10869-009-9141-1

McNall, L.A., A.D. Masuda and J.M. Nicklin, 2010 b. Flexible work arrangements, job satisfaction and turnover intentions: The mediating role of work to family enrichment. J. Psychol., 144: 61-81. DOI: $10.1080 / 00223980903356073$

Ministry of Education, Malaysia, 2008. Quick Facts 2013 Malaysia Educational Statistics. Malaysia: Educational Planning and Research Division, Ministry of Education Malaysia.

Ministry of Education, Malaysia, 2012. Preliminary Report Malaysia Education Blueprint 2013-2025. Malaysia: Human Resource Management Division, Ministry of Education.

Ministry of Education, Malaysia, 2013. Quick Facts 2013 Malaysia Educational Statistics. Educational Planning and Research Division, Ministry of Education Malaysia.

Ng, T.W. and K.L. Sorensen, 2008. Toward a further understanding of the relationships between perceptions of support and work attitudes: A metaanalysis. Group Organ. Manage., 22: 243-268. DOI: $10.1177 / 1059601107313307$

Nielson, T.R., D.S. Carlson and M.J. Lankau, 2001. The supportive mentor as a means of reducing workfamily conflict. J. Vocat. Behavior, 59: 364-381. DOI: $10.1006 /$ jvbe.2001.1806
Noraani, M., A. Aminah, U. Jegak and I. Khairuddin, 2011. Mediation effects of work-family factors on the relationship between dispositional characteristics and intention to stay among single mothers in Malaysia. Int. J. Bus. Social Sci., 2: 75-87.

Noryati, N., A. Aminah and B. Maznah, 2009. The mediating effect of work-family conflict on the relationship between locus of control and job satisfaction. J. Social Sci., 5: 348-354.

DOI: $10.3844 /$ jssp.2009.348.354

Odle-Dusseau, H.N., T.W. Britt and P. Bobko, 2012. Work-family balance, well-being and organizational outcomes: Investigating actual versus desired work/family time discrepancies. J. Bus. Psychol., 27: 331-343. DOI: 10.1007/s10869-011-9246-1

Roxburgh, S., 1999. Exploring the work and family relationship gender differences in the influence of parenthood and social support on job satisfaction. J. Family Issues, 20: 771-788. DOI: $10.1177 / 019251399020006003$

Ruderman, M.N., P.J. Ohlott, K. Panzer and S.N. King, 2002. Benefits of multiple roles for managerial women. Acad. Manage. J., 45: 369-386. DOI: $10.2307 / 3069352$

Russo, M. and F. Buonocore, 2012. The relationship between work-family enrichment and nurse turnover. J. Manag. Psychol., 27: 216-236. DOI: $10.1108 / 02683941211205790$

Sargent, T. and E. Hannum, 2005. Keeping teachers happy: Job satisfaction among primary school teachers in rural northwest China. Comparative Edu. Rev., 49: 173-204. DOI: 10.1086/428100

Shein, J. and C.P. Chen, 2011. Work-Family Enrichment: A Research of Positive Transfer. 1st Edn., Springer Science and Business Media, Rotterdam, ISBN-10: 9460913822, pp: 176.

Sieber, S.D., 1974. Toward a theory of role accumulation. Am. Sociological Rev., 39: 567-578. DOI: $10.2307 / 2094422$

Siu, O., J. Lu, P. Brough, C. Lu and A.B. Bakker et al., 2010. Role resources and work-family enrichment: The role of work engagement. J. Vocat. Behavior, 77: 470-480. DOI: 10.1016/j.jvb.2010.06.007

Skaalvik, E.M. and S. Skaalvik, 2011. Teacher job satisfaction and motivation to leave the teaching profession: Relations with school context, feeling of belonging and emotional exhaustion. Teac. Teac. Edu., 27: 1029-1038.

DOI: $10.1016 /$ j.tate .2011 .04 .001

Tang, S.W., O.L. Siu and F. Cheung, 2014. A study of work-family enrichment among Chinese employees: The mediating role between work support and job satisfaction. Applied Psychol., 63: 130-150. DOI: $10.1111 /$ j.1464-0597.2012.00519.x 
Taylor, B.L., R.G. DelCampo and D.M. Blancero, 2009. Work-family conflict/facilitation and the role of workplace supports for US Hispanic professionals. J. Organ. Behavior, 30: 643-664. DOI: $10.1002 /$ job.605

Thompson, C.A. and D.J. Prottas, 2005. Work-Family Culture: Key to Reducing Workforce-Workplace Mismatch? In: Workforce-Workplace Mismatch? Work, Family, Health and Well-Being, Bianchi, S.M., L.M. Casper and R. B. King (Eds.), Erlbaum Press, Mahwah, NJ, pp: 117-132.

Van den Berg, R., 2002. Teachers' meanings regarding educational practice. Rev. Edu. Res., 72: 577-625. DOI: $10.3102 / 00346543072004577$

Van Steenbergen, E.F., N. Ellemers and A. Mooijaart, 2007. How work and family can facilitate each other: Distinct types of work-family facilitation and outcomes for women and men. J. Occupat. Health Psychol., 12: 279-300.

DOI: $10.1037 / 1076-8998.12 .3 .279$

Voydanoff, P., 2004. The effects of work demands and resources on work-to-family conflict and facilitation. J. Marriage Family, 66: 398-412. DOI: $10.1111 / \mathrm{j} .1741-3737.2004 .00028 . \mathrm{x}$

Wadsworth, L.L. and B.P. Owens, 2007. The effects of social support on work-family enhancement and work-family conflict in the public sector. Public Admin. Rev., 67: 75-87.

DOI: $10.1111 / \mathrm{j} .1540-6210.2006 .00698 . x$
Wan Rashid, E.W., M.S. Nordin, A. Omar and I. Ismail, 2011. Social support, work-family enrichment and life satisfaction among married nurses in health service. Int. J. Social Sci. Hum., 1: 150-155. DOI: $10.7763 / \mathrm{IJSSH}$.2011.V1.26

Wayne, J.H., 2009. Reducing conceptual confusion: Clarifying the positive side of work and family. In: Handbook of Families and Work: Interdisciplinary Perspectives, Crane D.R. and J. Hill (Eds.), University Press of America, Lanham, MD, ISBN-10: 9780761844358, pp: 105-140.

Wayne, J.H., N. Musisca and W. Fleeson, 2004. Considering the role of personality in the workfamily experience: Relationships of the big five to work-family conflict and facilitation. J. Vocat. Behavior, 64: 108-130. DOI: 10.1016/S0001-8791(03)00035-6

Wayne, J.H., A.E. Randel and J. Stevens, 2006. The role of identity and work-family support in work-family enrichment and its work-related consequences. J. Vocat. Behavior, 69: 445-461. DOI: $10.1016 /$ j.jvb.2006.07.002

Weiqi, C., 2007. The structure of secondary school teacher job satisfaction and its relationship with attrition and work enthusiasm. Chin. Edu. Society, 40: 17-31. DOI: 10.2753/CED1061-1932400503

Yildirim, D. and Z. Aycan, 2008. Nurses' work demands and work-family conflict: A questionnaire survey. Int. J. Nurs. Stud., 45: 1366-1378. DOI: 10.1016/j.ijnurstu.2007.10.010 